\title{
Bench tests of a support system of a powered roof support's hydraulic leg aimed at minimizing consequences of leaks
}

\author{
Dawid Szurgacz ${ }^{1, *}$, Jarosław Brodny ${ }^{2}$, Marcin Brzózka ${ }^{3}$, and Ryszard Diederichs ${ }^{3}$ \\ ${ }^{1}$ Polska Grupa Górnicza S.A., KWK ROW Ruch Chwałowice, ul. Przewozowa 4, 44-206 Rybnik, \\ Poland \\ ${ }^{2}$ Silesian University of Technology, Faculty of Organization and Management, Roosevelta 26, 41-800 \\ Zabrze, Poland \\ ${ }^{3}$ DOH Hydraulics Center, ul. Konstytucji 147, 41-906 Bytom, Poland
}

\begin{abstract}
Effectiveness of a powered roof support significantly impacts on the efficiency and safety of a mining process. The main element of the support is a hydraulic leg which transfers loads imposed by the rock mass. One of the basic issues occurring during the extraction process are internal and external leaks of hydraulic systems. A new support system was designed to limit and later eliminate the consequences of such leaks. Its main component is a valve block equipped with two independent check valves. This solution allows to maintain high pressure in both chambers of a leg despite leaks. The article discusses the developed solution and presents preliminary results of bench tests of a leg equipped with the new block and loaded dynamically. The results are promising, and the tested block fulfils its task by maintaining the working pressure in the leg during load.
\end{abstract}

\section{Introduction}

Development of world economy is strongly affected by accesses to cheap energy sources. Despite the dynamic changes taking place in recent years, the basis for its development is still cheap and easily available energy [15]. The share of energy of renewable sources increases $[17,18]$, however, the energy obtained from conventional sources has the largest share in the global energy balance. Hard coal remains the basic raw material from which this energy is produced. Despite the increasing share of brown coal, crude oil and gas, hard coal production is still very high. The costs of energy generated from coal are the lowest, which means that it is widely used in its production. As a result, coal mining has been increasing in the world in recent years. The main factor that limits its exploitation in some regions of the world, mainly in Europe, concerns the impact it has on the environment. Both in the process of operation and during combustion. Many harmful gases and dust enter the environment both in the process of operation and during combustion. Various technical

\footnotetext{
*Corresponding author: dawidszurgacz@doh.com.pl
} 
and technological activities are undertaken to limit the impact. Nevertheless, it is indisputable that coal, due to its prevalence and price, will continue to be one of the dominant energy resources in the world.

In the entire process of energy and other products production (e.g. coke) from hard coal, effective and safe operation of the exploitation is essential. This raw material deposits underground and therefore its extraction is based on deep mining.

Currently, the most popular method of underground exploitation of hard coal is a longwall system. It is a highly efficient and relatively safe way of operation, whose stages can be mechanized $[4,16]$. This method applies powered roof support systems. The efficiency of the systems depends mainly on the effectiveness of its individual machines [4, $21,22]$. The main machines included in the systems are shearers or plow machines (designed to mine the rock mass), scraper conveyors (transporting the output) and a roof support whose main task is to protect the longwall working and support the whole unit. Effective and trouble-free operation of the support is fundamental as it decides on the entire coal mining process. Generally, it can be assumed that mining support, both for galleries and longwall excavations, is a basic factor impacting on the safety of underground mining operations.

The powered roof support comprises individual sections. They are connected with each other by means of hydraulic and control systems and are a uniform system protecting the area of operation in a longwall working. This is very important in the context of natural hazards occurring in the exploitation process. The most dangerous of these threats are ventilation and dust hazards [19, 23, 24, 25, 26]. Ventilation hazards include mainly methane and fire hazards, the development and extent of which depend on the effectiveness of the support operation and the extent to which it protects the cave-in zone [20, 23, 25, 27].

The wide scope of tasks that the support has to fulfil means that its selection and work are subject to special supervision.

The parameters of hydraulic legs operation are significant, as they are a basic loadbearing element of each section of a powered roof support. Obtaining adequate parameters of operation of hydraulic legs is the foundation for correct operation of the section and the entire unit. Therefore, it is necessary to conduct tests to determine the parameters of operation of these legs. This process is a major challenge for companies producing mining equipment. Mainly because they operate in very different mining and geological conditions. Consequently, they must be highly reliable and available.

One of the basic conditions determining the level of operational safety of a powered roof support section in a longwall excavation is its correct spragging. This requires proper initial load-bearing capacity that would ensure continuity of roof layers and adequate level of stress in the seam and the excavation's roof. The mining process is dynamic and therefore the bearing capacity of the support must be maintained for a set period of time and at required level. The section cannot lose its stability and the individual sections cannot slid down fully or partially during the mining process. For this reason, there are a number of studies that present various results of research and analyses related to the continuity of the mining process $[1,5,6,7,8,9]$.

Leg support diagnostic systems are increasingly used in order to ensure adequate support of the powered support section $[11,12]$. Unfortunately, they are not applicable everywhere. A drop in load-bearing capacity of legs during operation often occurs. One of the basic reasons are internal and external leaks of hydraulic fluid. This in particular concerns two-stage legs. Here, the unsealing occurs between the first and second stage, in the bottom seal or in the form of external unsealing.

Consequently, the fluid leaks or the pressure in the leg drops unexpectedly which leads to loss of load-bearing capacity. These are very dangerous phenomena that disturb the work of the entire support and cause a threat to the machines of the complex and the safety of 
employees. Any additional loads imposed by the rock mass are an additional factor that can lead to serious damage or destruction of these machines.

The occurrence of leaks in the hydraulic leg causes that it does not obtain the required support, which in turn may lead to increased convergence of the roof, resulting in the occurrence of roof falls or breaks in the continuity of the roof layers which in turn results in difficulties in the operation.

One of the reasons for such leaks in legs and the hydraulic system of the support section are frequent and difficult to predict static and dynamic overloads of the legs. The most common leakage is small but increases with the passage of time and subsequent cycles of operation of the section. Lack of system for monitoring section load-bearing capacity causes that such a leak may cause that the section will cease to transfer loads imposed by the rock mass.

For this reason, all types of pressure monitoring systems in the legs, which enable the detection of pressure anomalies resulting from leaks, are crucial. A well-functioning monitoring system can detect leaks already at a pressure lower than the initial load-bearing capacity. Therefore, the lack of such a system means that a leg with leaks, and consequently entire sections, operates for a long period of time without proper load-bearing capacity.

Detection of leaks must be followed by quick replacement of a leg that must be conducted each time the leak has been registered. Otherwise, a section with such a leg will pose a great threat to the effective operation of the entire support.

The authors developed and then tested an original system for detecting leaks in a leg and protecting it against consequences of such leaks. The paper discusses the developed system and presents preliminary results of its application in legs that were testes in a testing station. The results are highly promising. The authors believe that it is necessary to conduct further bench tests followed by underground tests to fully assess the system. Practical use of the system should significantly improve the parameters of the operation of the powered roof support's section and the safety of mining operation.

\section{Materials and Methods}

Currently, the commonly used hydraulic system for controlling the powered roof support' leg is equipped with a single control block with one check valve. This valve closes the fluid outflow from the space under the piston in the first stage of the leg. A diagram of this system with its basic elements marked is shown in Figure 1. I

$t$ is clear that in this system the second stage of the leg is not protected. The hydraulic fluid can flow out of it quite freely. In the event of external or internal leakage, this fluid may flow out through a drainpipe or canal without obtaining the required pressure.

It can be assumed that this system does not protect and does not provide the ability to control the pressure in the under-piston and over-piston part. 


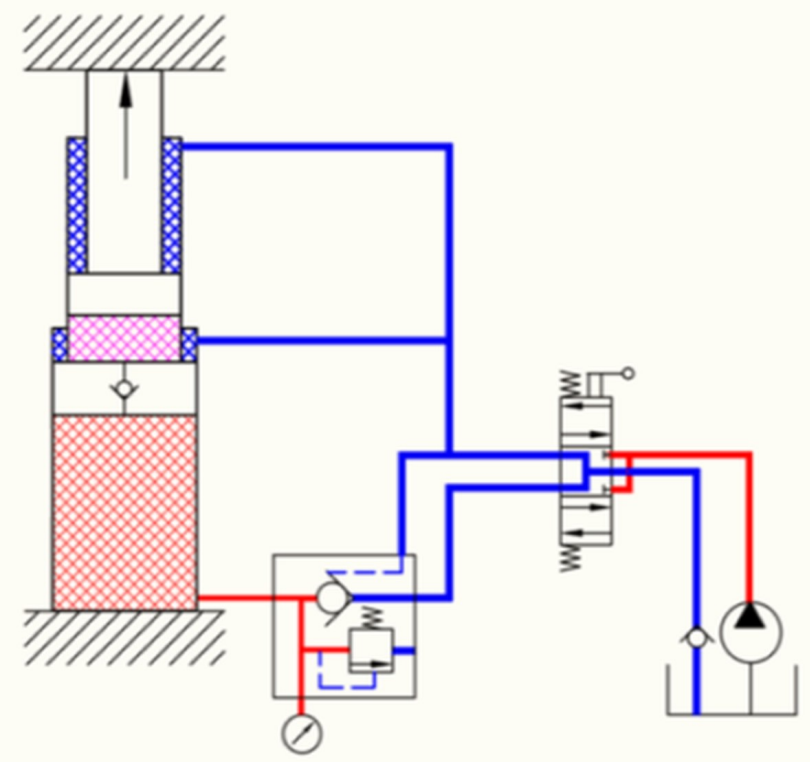

Fig. 1. Standard support system using a block with a single check valve.

The solution that removes some of these inconveniences is presented in Figure 2. This support system is equipped with a valve block which has two check valves.

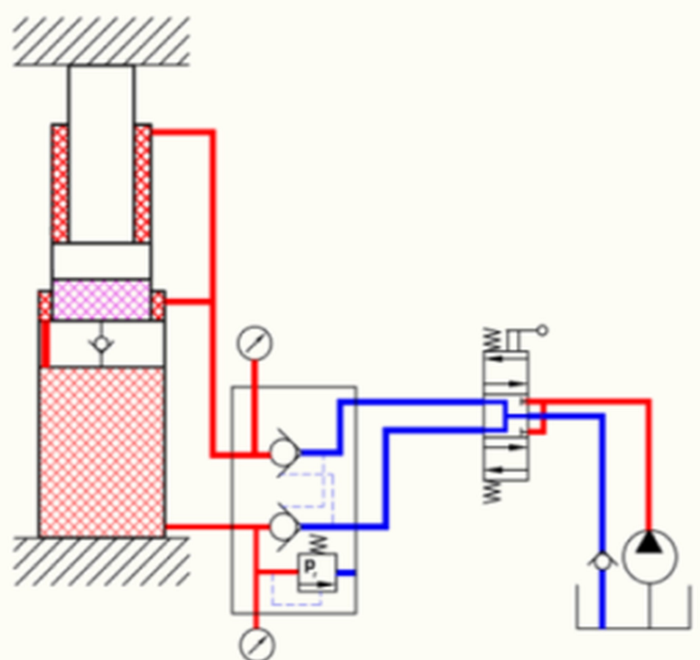

Fig. 2. A design of a support system using a block with a double check valve

The solution presented in Figure 2 is based on the idea that the fluid outflow from the under-piston and over-piston space is closed independently by means of two independent check valves. At the same time, the use of these valves in no way limits the functionality of the entire leg section or the entire support. A leg equipped with such a valve block performs the same function in a powered roof support section as a leg equipped with the hydraulic system used so far.

The undoubted advantage of the system shown in Figure 2 is that it maintains high pressure in the spacer over the piston. In the event of internal leakage of the leg, e.g. due to 
the pressure of the rock mass, the pressure of the fluid in the piston space increases, causing it to flow through the leaking piston seal to the space above the piston, from which it cannot flow into the main line. The second check valve maintains high fluid pressure in both chambers of the leg.

Pressure gauges were installed in the spaces above and under the piston in order to control the pressure in both chambers of the leg. This allows continuous control of the pressure in these spaces. This, in turn, gives the opportunity to check the technical condition of the leg for leaks. When the system indicates a leakage, the service team is required to either repair the damage or replace the leg. This monitoring enables quick response to occurring disorders and, consequently, effective response to occurring failures in the work of the leg.

The technical parameters of the overflow valves used in the block in the space under the piston are matched to a given leg in the same way as when used in the hydraulic system with a single block. The overflow valve is matched with the space above the piston and should be set to a pressure not greater than the working pressure of the lines connecting the valve with the block and the leg. The double valve block has an additional AM inlet that allows connection of a pressure sensor included in the pressure monitoring system of the legs.

Due to the fact that the outflow of fluid from the over-piston space is cut off by a check valve, no further flow of fluid through the hydraulic distributor to the drain main is possible. Therefore, the pressure in the over-piston space increases, allowing the pressure in the under-piston space to increase up to the value of the operating pressure limited by the setting of the overflow valve. Based on the pressure readings indicated by the $p_{p t}$ and $p_{n t}$ pressure gauges, it is possible to calculate the value of the pressure difference $p$ at which fluid leakage from the leg occurs from the following relationship:

$$
p=p_{p t}-p_{n},
$$

Fluid pressure in the space over the piston reduces the initial and working bearing capacity of the leg. The reduction in the working bearing capacity of the leg $P_{r}$ can be calculated knowing the hydraulic ratio of the leg $k$ (the ratio of the space over the piston to the space under the piston):

$$
{ }_{D} P_{r}=P_{r} \times k
$$

\section{Results and Discussion}

The biggest threat to all types of mining supports is the dynamic load imposed by the rock mass. Therefore, it is necessary to conduct tests under dynamic load both in case of gallery (yielding) [2,3] and hydraulic supports. This necessity also results from the fact that currently the frequency of such loads constantly increases. Deteriorating mining and geological conditions mean that the supports operate in increasingly extreme conditions. In particular, this applies to longwall excavations where there is a large accumulation of all types of hazards, which were already mentioned in the introduction of the article.

Therefore, the research team had decided to performed bench tests of the leg with dual hydraulic valve block in order to obtain sufficient assessment of the new solution (Fig. 2). The tested leg, equipped with a new support system, was dynamically loaded with freefalling impact mass.

The scheme of the testing station is shown in Figure $3 \mathrm{a}$ and the hydraulic leg mounted on the station is presented in Figure 3b. The tests were carried out on a specialized dynamic testing station located at TLO Opava in the Czech Republic. A free-falling mass was 
dropped on a cross bar placed on a leg. The results presented in the article show that the mass of the cross bar and the impact mass were constant. The change in the impact energy occurred as a result of the change in height from which the impact mass was dropped.

a)

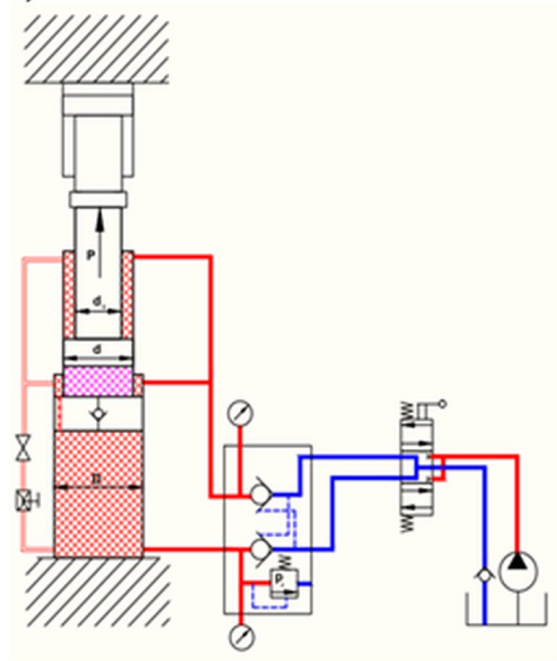

b)

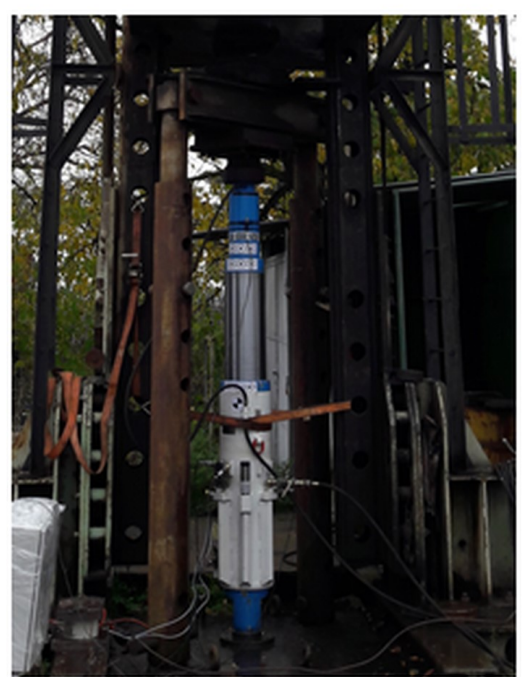

Fig. 3. Bench testing: a) a layout diagram of the system, b) the testing station

The tested leg was properly prepared so that the parameters necessary to determine internal leaks in its system could be registered. The conducted research provided a number of interesting results. Figures 4 and 5 show examples of pressure change patterns in the space under and over the piston.

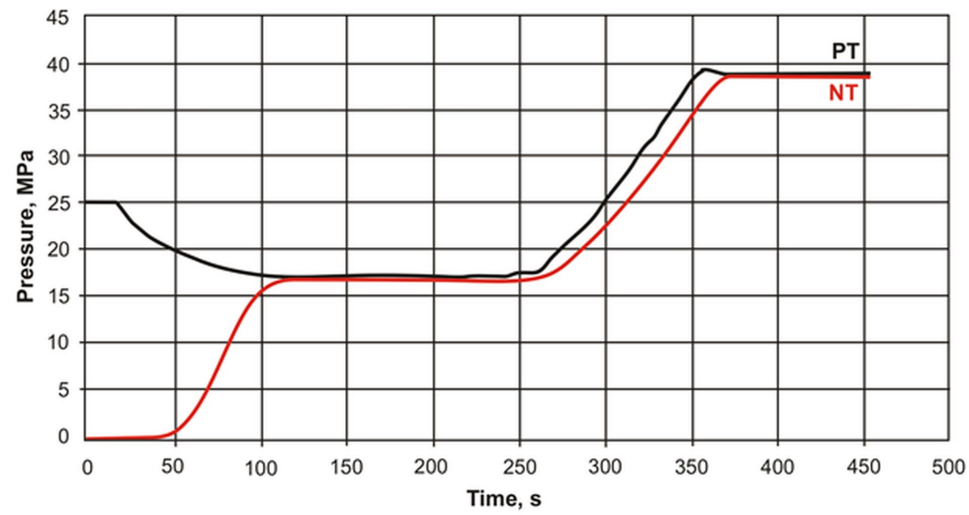

Fig. 4. The course of pressure changes in the space under and over the piston with a valve block at working pressure $\mathrm{P}_{\mathrm{r}}=25 \mathrm{MPa}$

The results indicate that as a result of a dropped impact there is a sudden increase in pressure in the space under and over the piston. The tested support system, using a double block, maintains pressure, preventing loss of support and stability of the leg. The recorded pressure waveforms (in Figure 4) indicate that the leg was slid out at a pressure of $25 \mathrm{MPa}$ in the space under the piston. The time after which the internal leak was detected was about $0.25 \mathrm{~s}$, and it took place at a pressure of about $18 \mathrm{MPa}$. The pressure in both chambers of the leg increased to approximately $38 \mathrm{MPa}$ as a result of dynamic loading. The system used 
did not allow the pressure to drop and maintained it almost at the same level. Thanks to the system, the leg carried external loads all the time, despite the leak.

\section{Conclusion}

The issues discussed in this paper have a significant impact of the mining process. Leaks in the hydraulic system are a very unfavourable phenomenon which is indicated by practical uses and tests in testing stations. They disturb the work of the leg and prevents the implementation of the basic functions of the section and the entire mining support. The problem concerns both the powered roof support section and individual legs used to secure mining excavations.

Tests were carried out using the developed valve block to minimize the effects of common internal leaks in hydraulic legs that. As provided by world recommendations in this area, the tests were carried out under dynamic loading using a drop weight tester [10, $13,14]$. The results clearly indicate that the proposed solution is very effective and allows minimizing the effects of leaks in a two-stage hydraulic leg. The application of the developed solution can significantly reduce any negative effects of leaks. It seems reasonable to replace valve blocks with a single check valve with blocks with two check valves. The authors believe that the presented solution will operate properly in underground excavations.

\section{References}

1. M. Blaschuk, A. Dronov, A. Koperchuk, R. Chernukhin, V. Litvienko, E3S Web of Conferences, 15, 03003 (2017)

2. J. Brodny, Arch. Min. Sci., Vol. 55:4, 733-746 (2010)

3. J. Brodny, Arch. Min. Sci., Vol. 56:2, 303-318 (2011)

4. J. Brodny, M. Tutak, Energies, 12, 2505, doi:10.3390/en12132505 (2019)

5. G. D. Buyalich, K. G. Buyalich, V. V. Voyevodin, IOP Conference Series: Materials Science and Engineering, 91, 012087 (2015)

6. G. D. Buyalich, K. G. Buyalich, V. V. Voyevodin, IOP Conf. Series: Materials Science and Engineering. - IOP Publishing, 127, 012034 (2016)

7. G. Buyalich, K. Buyalich, M. Byakov, E3S Web Conf., 21, (2017)

8. G. Buyalich, M. Byakov, K. Buyalich, E3S Web Conf., 41, (2018)

9. G. Buyalich, M. Byakov, K. Buyalich, E. Shtenin, E3S Web Conf., 105, 03025 (2019)

10. V. I. Klishin, T.M. Tarasik, Jour. of Min. Sci., 37, 77-84 (2001)

11. D. Szurgacz, J. Sust. Min., 14:4, 157-163 (2015) DOI: 10.1016/j.jsm.2015.12.001

12. D. Szurgacz, J. Brodny, SGEM, 17:13, 781-788 DOI: 10.5593/sgem2017/13/S03.099 (2017)

13. D. Szurgacz, J. Brodny, Sustainability, 11:9, 2570 (2019) doi.org/10.3390/su11092570

14. K. Stoiński, M. Mika, Jour. of Min. Sci., 39, 72-77 (2003)

15. S. Zhironkin, S. Demchenko, G. Kayachev, E. Taran, O. Zhironkina, E3S Web Conf., 105, 03008 (2019)

16. I. Yermakova, V. Fedusov, E3S Web Conf., 105, 01049 (2019)

17. M. Tutak, J. Brodny, 17th Intern. Multidisci. Sci. GeoConf. SGEM, Vienna GREEN Conference Proceedings, 17:43, 35-642; (2017) DOI: 10.5593/sgem2017H/43/S29.080 
18. K. Stecuła, J. Brodny, 17th Intern. Multidisci. Sci. GeoConf. SGEM2017, Vienna GREEN Conference Proceedings, 17:43, 749-756 DOI: 10.5593/sgem2017H/43/S29.094 (2017)

19. M. Tutak, SGEM2017 Vienna GREEN Conference Proceeding, 17:43, 301-308 DOI: 10.5593/sgem2017H/43/S19.038 (2017)

20. M. Tutak, 17th Intern. Multidisci. Sci. GeoConf. SGEM, Vienna GREEN Conference Proceedings, 17:15, 53-60 DOI: 10.5593/sgem2017H/15/S06.007 (2017)

21. J. Brodny, S. Alszer, J. Krystek, M. Tutak, Arch. of Cont.Sci. Vol. 27:LXIII:2, 197209 (2017) DOI : 10.1515/acsc-2017-0012

22. J. Brodny, M. Tutak, E3S Web Conf. 29 (2018) doi.org/10.1051/e3sconf/20182900014

23. J. Brodny, M. Tutak, Jour.l of Appl. Flu. Mech., 11:3, 545-553 (2018) DOI: 10.18869/acadpub.jafm.73.246.27240

24. J. Brodny, M Tutak, Intern. Jour. of Envir. Rese. and Pub. Hea. 15:9, 1-16 (2018) 10.3390/ijerph15091846

25. M. Tutak, J. Brodny, Energies, 11(11), 3076, pp. 1-28. doi.org/10.3390/en11113076 (2018)

26. J. Brodny, M. Tutak, 16th Intern. Multid. Sci. GeoConf. SGEM, 1:2, pp. 75-82, (2016)

27. M. Tutak, J. Brodny, IOP Conf. Ser. Earth Environ. Sci., 95, 042025 (2017) 